\title{
ADOPSI KEBIJAKAN PENGARUSUTAMAAN GENDER DALAM ORGANISASI FATAYAT
}

\author{
Mami Hajaroh \\ Fakultas Ilmu Pendidikan Universitas Negeri Yogyakarta \\ email: mami_hajaroh@uny.ac.id
}

\begin{abstract}
Abstrak: Adopsi Kebijakan Pengarusutamaan Gender dalam Organisasi Fatayat. Penelitian ini bertujuan untuk menemukan faktor-faktor penentu dalam adopsi pengarusutamaan gender/PUG dan mengidentifikasi proses inovasi PUG di organisasi Fatayat DIY. Penelitian menggunakan paradigma konstruktivisme dengan pendekatan kualitatif fenomenologi. Subjek penelitian adalah anggota Fatayat DIY, sumber informasi ditentukan dengan snow ball sampling. Pengumpulan data menggunakan teknik in depth interview. Data dianalisis dengan Interpretative Phenomenological Analysis. Hasil penelitian menunjukkan bahwa adopsi pengarusutamaan gender di Fatayat DIY ditentukan oleh faktor internal dan eksternal. Faktor internal meliputi: PUG merupakan hal baru yang dibutuhkan Fatayat; PUG relevan dengan nilai-nilai dan norma agama; dan karakteristik terbuka pada pemimpin opini dalam organisasi; dan struktur organisasi Fatayat DIY. Faktor eksternal meliputi: restu dari Nahdlatul Ulama sebagai organisasi induk; gencarnya gerakan gender dari gerakan global; dan dukungan dana dari luar negeri. Proses inovasi kebijakan PUG dalam organisasi meliputi tahap melakukan setting agenda, penyesuaian, mendefinisikan kembali, mengklarifikasi, dan merutinkan.
\end{abstract}

Kata kunci: adopsi, pengaruautamaan gender, Fatayat, organisasi

\begin{abstract}
The Adoption of Gender Equality Policy in Yogyakarta Fatayat Organization. This study was aimed at finding out the determining factors in the adoption of gender equality and identifying the innovation processes in the Fatayat organization. The study used a qualitative approach constructivism with phenomenology. The subjects were the members of Fatayat in Yogyakarta while the resources were determined by the snow ball sampling. The data were collected using in depth interview technique. Then the data were analyzed using Interpretative Phenomenological Analysis. The results show that the adoption of gender equality at Fatayat DIY determined by internal and external factors. Internal factors include: gender equality is a new thing that is needed by Fatayat; it is relevant to the values and norms of religion; and the transparant characteristic of leaders within the organization; and organizational structure of Fatayat. External factors include: the approval of Nahdlatul Ulama as a main organization; the incessant movement of the gender of the global movement; and financial support from abroad. Gender equality policy innovation process in the organization includes the step of setting the agenda, adjustments, redefine, clarify and sustainability.
\end{abstract}

Keywords: adoption, gender equality, Fatayat, organization 


\section{PENDAHULUAN}

Kebijakan pengarusutamaan gender (PUG) sebagai strategi pembangunan didifusikan secara transnasional sejak tahun 1975. Kebijakan ini diadopsi oleh Indonesia secara resmi oleh pemerintah dengan mengeluarkan Instruksi Presiden RI Nomor 9 Tahun 2000 tentang Pengarusutamaan Gender dalam Pembangunan Nasional tertanggal 19 Desember 2000. Difusi kebijakan pengarusutamaan gender ke dalam organisasi/institusi dan kepada anggota/ individu merupakan proses penting dalam dinamika perkembangan organisasi baik organisasi pemerintah (goverment) maupun nonpemerintah (governance).

Kebijakan strategi pembangunan pengarusutamaan gender menuntut peran perempuan yang lebih besar dalam berbagai sektor pembangunan, termasuk dalam lembaga legislatif, eksekutif, dan yudikatif. Meningkatnya jumlah perempuan di lembaga tersebut secara signifikan dapat memperkecil hambatan-hambatan dalam pelaksanaan pengarusutamaan gender. Untuk itu perempuan yang memasuki lembaga publik harus siap secara mental, moral, materi, dan ilmu untuk berjuang bagi tercapainya kesetaraan. Keberhasilan strategi pengarusutamaan gender dalam mengubah kehidupan masyarakat sangat ditentukan oleh difusi yang dilakukan. Difusi kebijakan yang terjadi menentukan keputusan adopsi pada organisasi biasanya dengan menyusun kebijakan yang responsif gender dalam organisasi.

Difusi inovasi terjadi dalam suatu sistem sosial yang di dalamnya terdapat struktur sosial, individu atau kelompok individu, dan norma-norma tertentu. Secara teoretis dalam Yalcinkaya (2007: 9) teori difusi inovasi menggambarkan pola-pola adopsi, menjelaskan mekanisme terjadinya inovasi dan membantu memprediksi apakah difusi akan berhasil. Rogers (2003: 12) menyebutkan bahwa inovasi adalah suatu ide, praktik atau objek yang dianggap sebagai sesuatu yang baru oleh seorang individu atau satu unit adopsi lain. Inovasi menurut Havelock (tth: 2-1) adalah membuat keputusan perubahan dan dengan sikap penuh harapan untuk memperbaiki cara melakukan sesuatu dengan menggunakan sesuatu yang baru. Selanjutnya Rogers (2003: 15-17) mengemukakan lima karakteristik inovasi yang meliputi: (1) keunggulan relatif (relative advantage); (2) kompatibilitas (compatibility); 3) kerumitan (complexity); 4) dapat diujicobakan (trialability); dan 5) dapat diamati (observability).

Berkaitan dengan itu Damanpour (1996: 694) menyatakan bahwa inovasi dapat dipelajari pada level firma, industri atau level individual. Inovasi pada level organisasi didefinisikan sebagai adopsi ide-ide atau perilaku baru bagi organisasi pengadopsi (Daft, 1978; Damanpour \& Evan, 1984). Adopsi inovasi mengandung arti sebagai sebuah proses dikembangkan dan diimplementasikannya ide-ide dan perilaku baru yang masuk pada satu generasi. Inovasi selain bermakna perubahan pada organisasi, juga sebuah respons perubahan pada lingkungan eksternal organisasi. Inovasi didefinisikan secara luas dengan menekankan pada beberapa tipe, termasuk produk atau layanan baru, teknologi baru, dengan struktur organisasi atau sistem administrasi atau yang berkaitan dengan rencana-rencana dan program baru pada organisasi.

Greenhalg et al. (2004: 582) membedakan pengertian antara difusi, diseminasi, dan implementasi. Menurutnya diseminasi merupakan proses persebaran yang bersifat pasif, difusi merupakan 
usaha yang aktif dan direncanakan untuk mempengaruhi kelompok target agar mengadopsi inovasi. Sedangkan implementasi merupakan usaha aktif dan direncanakan untuk mengarusutamakan sebuah inovasi dalam organisasi. Keberlanjutannya adalah membuat inovasi menjadi kebiasaan sehari-hari untuk menghilangkan kekunoan.

Secara umum menurut (Yalcinkaya, 2007: 10) terdapat dua klasifikasi besar dalam penelitian difusi inovasi yakni model level makro (Macro-Level/Aggregate) dan level mikro (Micro Level/Individual). Model makro adalah model difusi yang menguji agregasi pasar dan asumsi homogenitas dalam populasi adopter. Sedangkan model mikro secara spesifik fokus pada perilaku adopter individual dan diasumsikan bahwa adopsi inovasi mendasar pada setiap individu yang berbeda dan invividu adalah personal yang pelik.
Gambar 1 menunjukkan proses inovasi dalam organisasi (Rogers, 2003: 420-430) merupakan level makro. Level ini terdiri atas dua aktivitas yang luas, yakni: pertama, inisiasi yang didefinisikan sebagai semua kumpulan informasi, konseptualisasi dan perencanaan untuk adopsi inovasi, dan memimpin keputusan untuk adopsi. Inisiasi meliputi tahap agenda-setting dan matching. Kedua, implementasi yaitu semua kejadian, tindakan dan keputusan yang rumit dalam pengambilan inovasi untuk digunakan. Implementasi meliputi tahap redefining/ restructuring, clarifying, dan routinizing.

Kebijakan stategi pembangunan pengarusutamaan gender (Gender Mainstreaming) adalah kebijakan global yang merupakan inovasi kebijakan dalam rangka perubahan kehidupan yang berkeadilan dan berkesetaraan gender dideklarasikan pada tahun 2000 di Beijing. Hasil penelitian True dan Mintrom (2001:

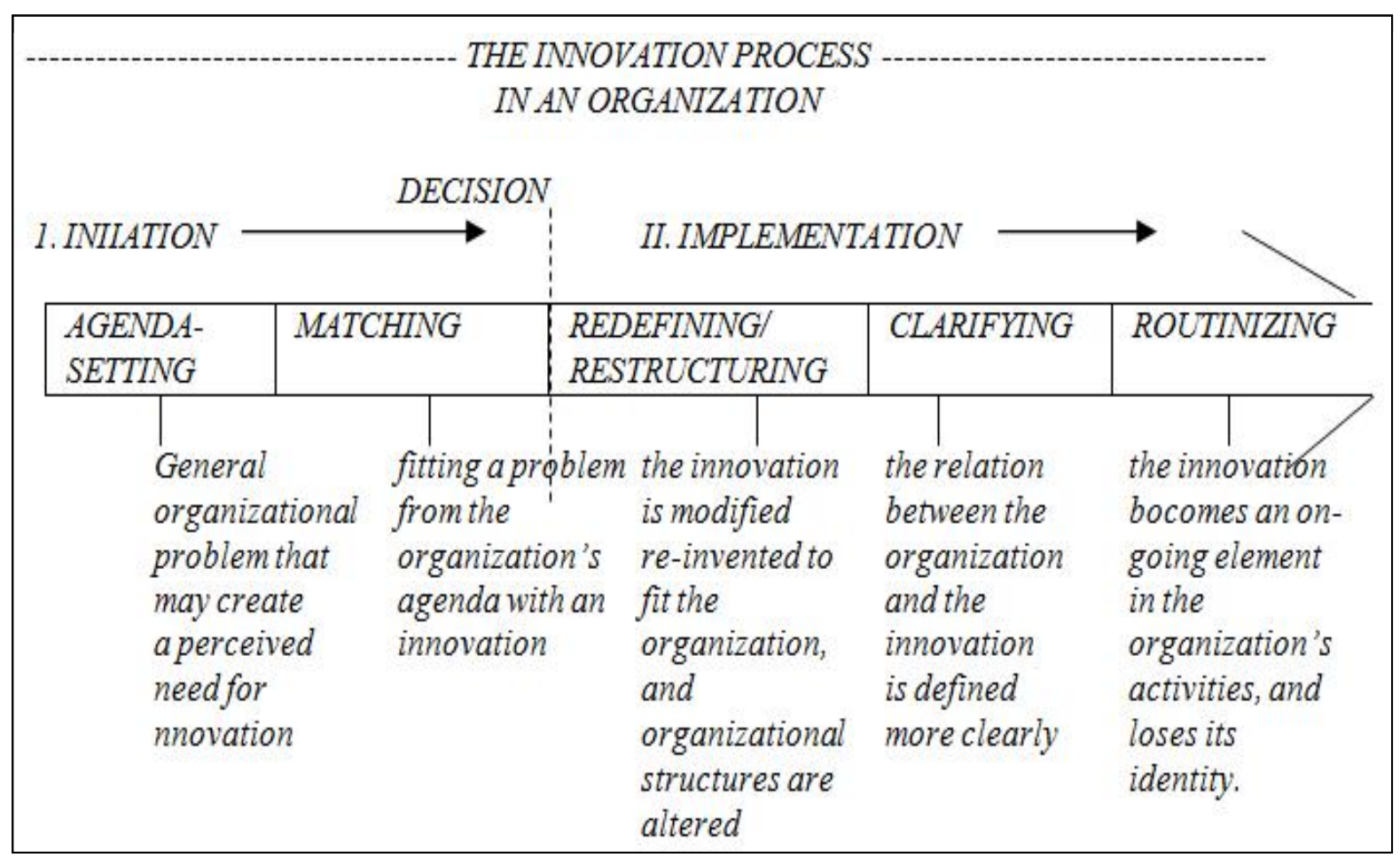

Gambar 1. Lima Tahap Proses Inovasi dalam Organisasi (Rogers, 2003: 421) 
32) tentang Transnational Networks and Policy Diffusion dengan topik difusi global dari mekanisme Institusional untukgender mainstreaming menunjukkan terjadinya adopsi pengarusutamaan gender. Fatayat mengadopsi kebijakan pengarusutamaan gender secara progresif dengan menyusun visi dan misi fatayat menjelang kongres tahun 2000, padahal Fatayat dikenal sebagai organisasi perempuan muda yang berada dalam budaya patriarkhi dengan nilai-nilai dan norma Islam tradisional. Dengan mengadopsi PUG berarti Fatayat bertemu dengan nilainilai dan norma kesetaraan dan keadilan gender yang didifusikan oleh jaringan transnasional yang liberal dan sekuler. Islam tradisional dan budaya partiarkhi berhadapan dengan modernitas yang sekuler dan liberal. Pada poin inilah penting untuk dilakukan penelitian, yakni pada proses mengomunikasikan sehingga organisasi mengadopsi PUG.

\section{METODE}

Penelitian ini menggunakan paradigma konstruktivisme dan pendekatan kualitatif fenomenologi. Subjek penelitian adalah anggota Fatayat yang duduk dalam kepemimpinan pada tingkat cabang, wilayah dan pimpinan pusat di DIY yang ditentukan dengan teknik sampel bertujuan (purposive sampling) dengan teknik bola salju (snow ball sampling). Objek penelitian adalah belajar yang terjadi dalam difusi kebijakan pengarusutamaan gender. Teknik pengumpulan data menggunakan in depth interview.

Analisis data menggunakan Interpretative Phenomenological Analysis (IPA). Analisis fenomenologi ini bertujuan untuk mengungkap secara detail bagaimana subjek memaknai dunia personal dan sosialnya yang berkaitan dengan pengarusutamaan gender. Dengan sasaran utama adalah makna berbagai pengalaman, peristiwa dan status yang dimiliki oleh subjek serta mengeksplorasi pengalaman personal yang menekankan pada persepsi atau pendapat mereka mengenai pengarusutamaan gender. Interpretative Phenomenological Analysis meliputi tahap: (a) reading and re-reading; (b) initial noting; (c) developing emergent themes; (d) searching for connections across emergent themes; (e) moving the next cases; dan (f) looking for patterns across cases.

\section{HASIL DAN PEMBAHASAN \\ Adopsi Pengarusatamaan Gender pada Organisasi Fatayat}

Adopsi pengarusutamaan gender oleh individu anggota Fatayat menginspisari anggota Fatayat untuk melakukan perubahan dalam masyarakat yang lebih luas dengan melakukan difusi PUG dalam organisasi (Hajaroh, 2012: 286). Riana sebagai Ketua 2 PP Fatayat menginisiasi agar kesetaraan dan keadilan gender menjadi kebijakan dan program organisasi secara nasional. Di samping itu, di tingkat wilayah DIY telah terjadi gejolak resistensi terhadap beberapa isu kesetaraan dan keadilan gender yang digulirkan. Anggota Fatayat DIY melakukan konfirmasi mengenai isu-isu tersebut dengan keinginan mendapat "penyikapan balik" dari PP Fatayat. Penyikapan balik yang dimaksukan adalah agar Fatayat menentukan sikap berkait dengan isu-isu kesetaraan dan keadilan gender yang digulirkan untuk memutuskan aspek manakah yang dapat diterima dan aspek mana pula yang tidak diterima karena ada beberapa isu yang diangkat kelihatan tidak sejalan dengan nilai dan norma Islam yang telah dipahami.

Kegiatan awal menginisiasi kebijakan dan program gender dalam organisasi 
dilakukan dengan menyelenggarakan Lokakarya Nasional pada tahun 1998. Lokakarya dimaksudkan untuk membuat kebijakan dan program agar Fatayat secara aktif dan progresif menggarap isu-isu kesetaraan dan keadilan gender. Selain itu, agar gerakan kesetaraan gender ini mendapat "restu" dari banyak pihak di kalangan NU. Oleh karena itu, dalam lokakarya diundang sejumlah kiai NU. Kebijakan dan program kesetaraan ini pada awalnya "tidak mendapat restu sepenuhnya" dengan adanya ungkapan yang diberikan oleh NU kepada Fatayat, "kalau begitu silakan tapi harus ingat rambu-rambunya". Bagi Fatayat ramburambu yang diberikan oleh kalangan Kiai disadari sebagai sebuah keharusan untuk diikuti sebagaimana disampaikan Riana: "saya pikir ini sebuah keharusan kita, karena kita sebagai bagain dari NU, apalagi Fatayat badan otonom NU ya berkewajiban menjaga nilai-nilai NU".

PP Fatayat melakukan inovasi organisasi dengan membuat kebijakan PUG. Proses inovasi yang dilakukan oleh PP Fatayat bertujuan untuk memberikan perubahan kehidupan yang lebih adil dan setara gender kepada perempuan anggota Fatayat dan perempuan pada umumnya. Tabel 1 menunjukkan proses inovasi yang dilakukan oleh PP Fatayat. Dari Tabel 1 tampak bahwa Fatayat sebagai organisasi masyarakat menjadi organisasi yang memiliki keinovatifan dengan membuat kebijakan PUG. Inovasi yang dibuat berhasil didifusikan dan diadopsi dalam organisasi oleh anggotaanggota organisasi.

Proses inovasi organisasi Fatayat ini sejalan dengan alur proses inovasi dalam organisasi sebagaimana yang dikemukan oleh Rogers (2003: 420-430). Proses inovasi dalam organisasi terdiri atas dua aktivitas yang luas, yakni: pertama, inisiasi yang didefinisikan sebagai semua kumpulan informasi, konseptualisasi dan perencanaan untuk adopsi inovasi, dan memimpin keputusan untuk adopsi. Inisiasi meliputi dua tahap, agenda-setting dan matching. Kedua, implementasi. Implementasi adalah semua kejadian, tindakan dan keputusan yang rumit dalam pengambilan inovasi untuk digunakan. Sedangkan implementasi meliputi tiga tahap yakni: redefining/restructuring, clarifying, dan routinizing.

Kebijakan Fatayat mengadopsi kesetaraan dan keadilan gender dari gerakan perempuan global dengan cara memodifikasi sesuai dengan versi Fatayat. Program gender dan penguatan terhadap hak-hak perempuan dimulai dengan melakukan kegiatan pelatihan secara intensif mengenai analisis gender dan melakukan workshop gender di tujuh provinsi di Indonesia termasuk DIY. Program ini berlangsung selama dua tahun (1998-1999). Dengan pelatihan dan workshop mengenai hak-hak perempuan menumbuhkan kesadaran baru di kalangan anggota Fatayat walaupun sekaligus juga menimbulkan tantangan baru bagi Fatayat. Isu-isu gender terutama penguatan hak-hak perempuan lebih banyak menjadikan perempuan semakin sadar, kita membutuhkan banyak hal, akan tetapi di satu sisi bagaimana ini dikatakan kita mengajari seorang isteri melawan suami, kita mengajari sebagai warga negara untuk memberontak negara. Demikian ditegaskan Riana.

Fatayat DIY bersentuhan dengan isu-isu gender mulai tahun 1994-1995. Menurut Marhamah pada tahun 19951996 YKF yang didirikan oleh PW Fatayat DIY telah bekerja sama dengan Ford Foundation menyelenggarakan pelatihan analisis gender. Namun, saat itu terjadi penolakan terhadap isu-isu gender yang 


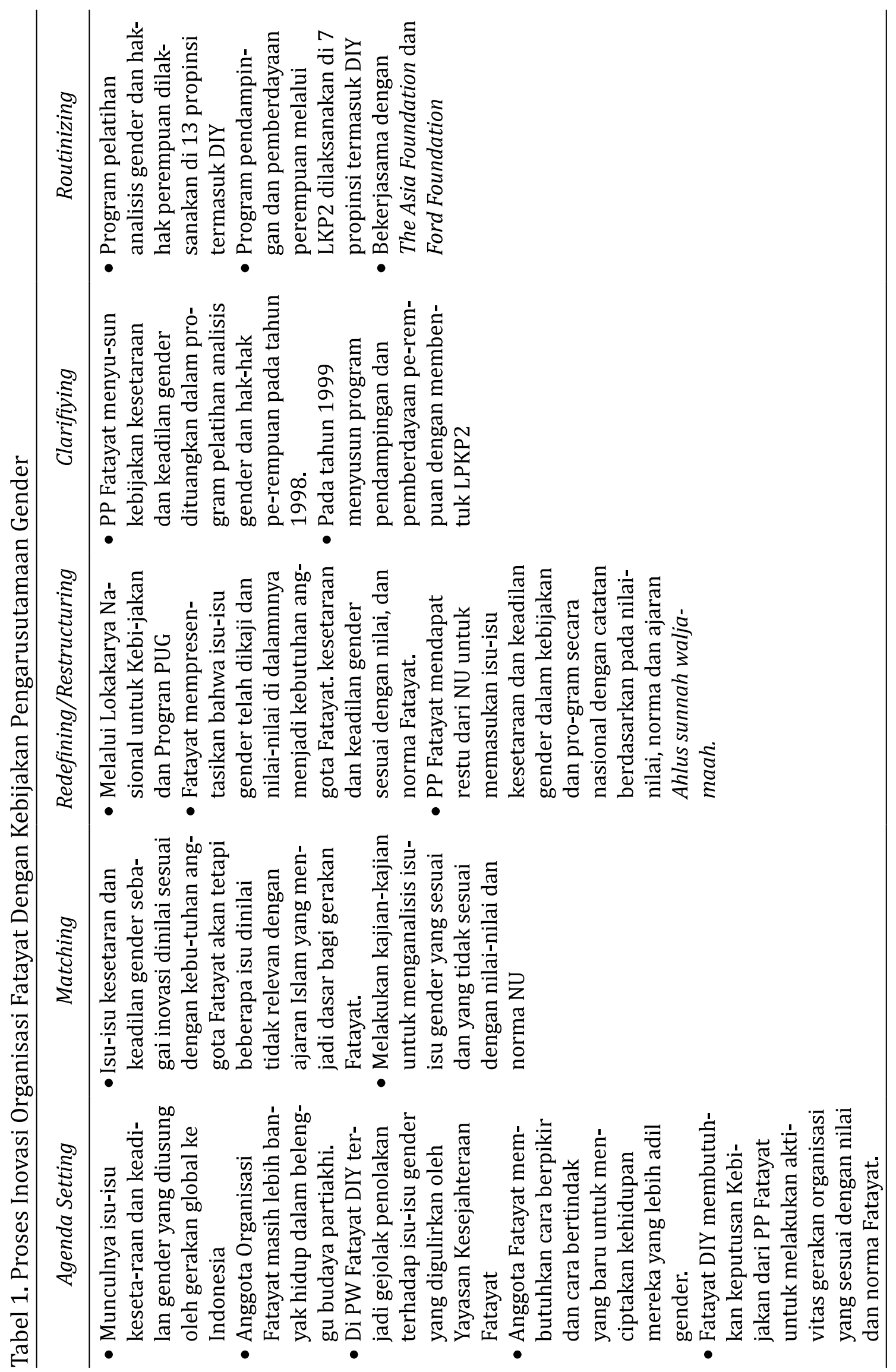


digulirkan dari berbagai kalangan, baik dari Fatayat, tokoh-tokoh NU, maupun tokoh pesantren terhadap apa yang dilakukan oleh YKF.

Di kalangan tokoh NU, tokoh pesantren dan kiai muda yang berpendidikan yang membaca kitab-kitab klasik penilakan yangterjadi relatif dalam waktu yang sebentar saja. Para kiai dan nyai serta tokoh-tokoh NU ketika diberikan dalil dengan cepat, mereka menangkap dan memahaminya. Kondisi yang berbeda ketika dalil diberikan kepada Fatayat. Resistensi Fatayat dalam bentuk "ketakutan" akan ada perubahanperubahan yang berbeda dengan apa yang telah mereka pelajari dari guru mereka. Kegelisahan Fatayat DIY terhadap issu kesetaraan dan keadilan gender terjawab dengan kebijakan program PP Fatayat tentang Gender dan Hak-hak Perempuan pada tahun 1998. Kesetaraan dan keadilan gender yang didifusikan oleh PP Fatayat melalui Program Gender dan Hak-hak Perempuan sudah mengalami proses analisis yang melibatkan tokohtokoh NU.

Pada Konggres Fatayat ke XII di Bandung pada tanggal 5-9 Juli 2000 Fatayat memutuskan tentang visi dan misi yang responsif gender. Padahal pemerintah Indonesia mengadopsi Pengarusutamaan Gender dengan mengeluarkan Inpres Nomor 9 baru pada tanggal 9 Desember 2000. Dalam hal ini kebijakan Fatayat mendahului kebijakan pemerintah. Riana menegaskan,

"kalau kita lihat dari proses pergulatan ini nampaknya saya melihat bahwa gender mainstreaming Fatayat ini lebih dulu dari pada keluar Inpres no 9 th 2000 pada periodenya mbak Khafifah, Sebelum tahun 2000 sudah me-mainstreaming-kan perspektif gender dalam kebijakan Fatayat".
Merumuskan visi dan misi organisasi Fatayat NU dengan perspektif kesetaraan dan keadilan ini dilakukan lima bulan lebih awal dari Inpres Nomor 9 Tahun 2000 yang diinstruksikan pada bulan Desember 2000. Pada rumusan visi dan misi yang ditetapkan (PP Fatayat, 2000: 81-82) menuangkan gagasan betapa pentingnya perempuan memiliki kehidupan yang berkeadilan dan berkesetaraan gender. Visi dan misi Fatayat mendorong dan memotivasi Fatayat DIY untuk mengimplementasikan kebijakan tersebut ke dalam program dan kegiatan organisasi.

Apabila ini dianalisis dari paradigma kebijakan, tampak bahwa kebijakan pengarusutaman gender merupakan kebijakan yang menggunakan paradigma sosial. Inpres Nomor 9 Tahun 2000 tentang Pengarusutamaan Gender dalam Pemerintah muncul karena adanya dukungan dari berbagai elemen masyarakat termasuk Fatayat. Kebijakan pengarusutamaan gender merupakan kebijakan yang bersifat bottom up dari masyarakat yang dibawa ke dalam kebijakan publik.

Berbagai program kesetaraan dan keadilan gender yang dilaksanakan oleh Fatayat tahun 2000-2010 menunjukkan bahwa PUG telah menjadi bagian dari Fatayat. Proses yang terjadi di DIY khususnya Kulon Progo pada tahun tersebut merupakan proses adopsi inovasi organisasi pada tahap merutinkan (Rogers, 2003: 246). Merutinkan merupakan suatu tahap yang inovasinya menjadi bagian dari aktivitas organisasi dan organisasi kehilangan identitas sebelumnya. Identitas Fatayat sebagai organisasi perempuan tradisional dengan aktivitas dari "ngaji ke ngaji" mulai hilang. Fatayat bukan lagi sekelompok perempuan muda pedesaan yang termarginalkan dalam informasi tetapi telah berubah menjadi kelompok 
perempuan muda yang progressif dan inovatif serta mampu menjadi penggerak bagi perempuan lain di sekitarnya.

Aktivitas perempuan Fatayat di ruang publik yang merupakan perwujudan dari kesetaraan dan keadilan gender telah menjadi aktivitas yang wajar, lazim, dan dapat diterima. Perbicangan tentang kesetaraan dan keadilan gender sudah mejadi hal yang lazim dan biasa di antara anggota organisasi dan masyarakat luas juga sudah mulai mengenal nilai-nilai dan norma kesetaraan tersebut. Semua ini merupakan hasil hari merutinkan. Namun demikian, aktivitas merutinkan tetap harus dilakukan secara terus-menerus karena mewujudkan kehidupan masyarakat yang adil gender membutuhkan waktu yang tidak singkat.

Gambaran mengenai faktor-faktor penentu dalam adopsi kebijakan pengarusutamaan gender dalam organisasi Fatayat dapat dilihat pada Gambar 2.
Gambar 2 menunjukkan kondisi internal dan eksternal organisasi yang menjadi faktor penentu dalam adopsi kebijakan pengarusutamaan gender. Kebutuhan pada konsep kesetaraan dan keadilan bagi anggota, relevansi dengan nilai-nilai dan norma agama, karakteristik pemimpin opini dalam organisasi serta struktur organisasi yang dimiliki menentukan terjadinya adopsi kebijakan pengarusutamaan gender. Sikap NU sebagai organisasi induk dengan memberikan restu menjadi penentu utama dalam proses ini. Gencarnya gerakan perempuan di luar Fatayat dengan dana yang dibawa menjadi faktor eksternal yang menentukan bagi Fatayat dalam melakukan difusi inovasi kebijakan Pengarusutamaan Gender.

\section{Eforia Politik Perempuan sebagai Ben- tuk Adopsi Pengarusutamaan Gender}

Kesadaran perempuan terhadap hak di ruang publik mendorong perempuan

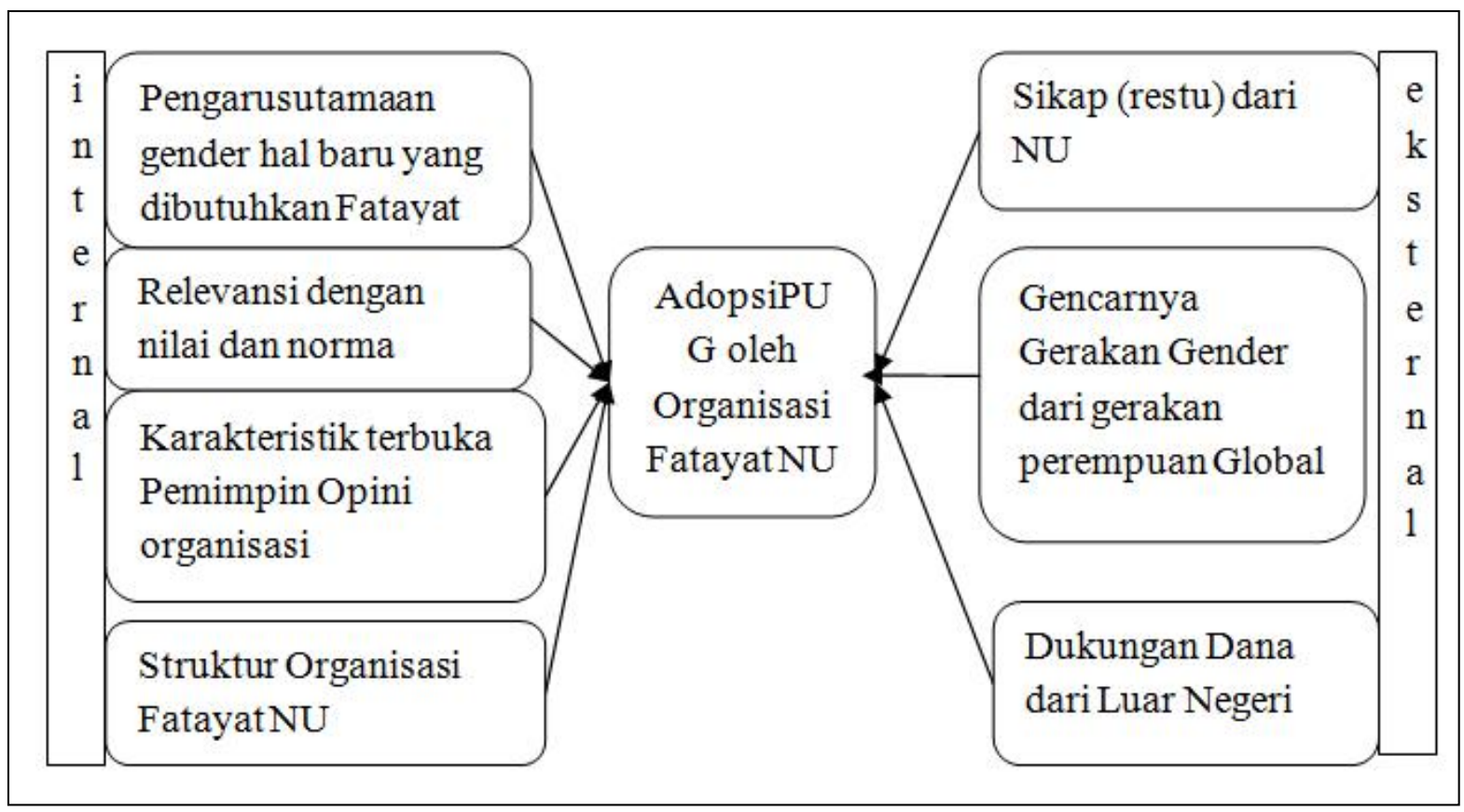

Gambar 2. Faktor-faktor Penentu Adopsi Kebijakan Pengarusutamaan Gender 
Fatayat untuk bergerak lebih jauh dalam ranah publik. Pada tahun 1999 pada pemilihan umum legislatif menjadi ajang perempuan Fatayat untuk terlibat aktif mewujudkan pengaurustamaan gender dalam kebijakan publik. Partisipasi diwujudkan dalam bentuk aktif di partai politik dan pencalonan legislatif. Anggota Fatayat yang berminat dalam politik saat itu mendapat dukungan penuh dari organisasi, meskipun secara organisatoris Fatayat tidak berafiliasi dalam partai politik. Sebagai pribadi anggota Fatayat dapat terlibat dalam kancah politik. Berawal dari kesadaran pribadi pengurus organisasi dan responsibilitas pascapelatihan gender memunculkan keinginan untuk melaksanakan PUG melalui politik.

Undang-Undang Nomor 10 Tahun 2008 tentang Pemilu Legislatif menjelaskan bahwa kuota keterlibatan perempuan dalam dunia politik adalah sebesar 30 persen. Dalam Pasal 8 huruf d UU Nomor 10 Tahun 2008 disebutkan, penyertaan sekurang-kurangnya 30 persen keterwakilan perempuan pada kepengurusan parpol tingkat pusat sebagai salah satu persyaratan partai politik untuk dapat menjadi peserta pemilu. Pasal 53 UU Nomor 10 Tahun 2008 tentang Pemilu Legislatif mengatakan bahwa daftar bakal calon peserta pemilu juga harus memuat paling sedikit 30 persen keterwakilan perempuan tak lagi cukup menyemangati Fatayat Kulon progo untuk bergerak maju pada pemilu tahun 2009.

Dampak langsung dari adopsi kebijakan pengarusutamaan gender bagi perempuan Fatayat secara organisatoris untuk mengimplementasikan PUG dalam pengambilan kebijakan publik. Realisasi upaya tersebut dengan berpartisipasi dalam pemilu dari tahun 1999, 2004 dan 2009 agar suara perempuan diwakili dalam perlemen dan dapat terlibat secara langsung dalam pembuatan keputusan kebijakan yang responsif gender.

Dampak atau dalam istilah Rogers konsekuensi (consequens) adalah perubahan-perubahan yang terjadi baik pada individu-individu maupun sistem sosial sebagai hasil dari adopsi inovasi (2003: 30). Keterlibatan perempuan Fatayat pada pemilu 1999 merupakan dampak langsung dari adopsi pengarusutamaan gender yang ditandai dengan dibukanya kran untuk partisipasi perempuan dalam pengambilan kebijakan publik. Partisipasi dimaksud adalah partisipasi dalam pengambilan kebijakan di parlemen atau legislasi. Oleh karena itu pada pemilu 1999 mencalonkan diri sebagai anggota legislatif menjadi salah satu peluang yang dapat segera diambil oleh perempuan Fatayat setelah mengikuti program pelatihan gender dan hak-hak perempuan. Salah satu bukti bahwa mereka menerima dan melaksanakan PUG adalah berpartisipasi aktif dalam pemilu tak hanya sebagai pemilih tetapi juga berhak untuk dipilih.

Eforia yang terjadi perempuan Fatayat beramai-ramai mencalonkan diri hampir di setiap daerah pemilihan di Kulon Progo, lobi kepada kiai untuk mendapatkan dukungan merupakan dampak langsung bahwa adopsi pengarusutamaan gender telah terjadi. Legislasi pemilu 1999 pintu pertama yang terbuka beriring dengan gerakan kesetaraan dan keadilan gender yang telah masuk ke Indonesia. Pada saat itu juga pintu reformasi Indonesia tengah dibuka dengan lengsernya Orde Baru. Pada pemilu 1999 menjadi even penting bagi perempuan untuk membuktikan diri bahwa mereka mampu dan mau berpatisipasi dalam pengambilan keputusan walaupun pada akhirnya mereka kecewa karena keberhasilan belum mereka peroleh. 


\section{Yayasan Kesejahteraan Fatayat (YKF) sebagai Akselerasi Difusi Kebijakan Pengarusutamaan Gender dalam Organisasi}

Yayasan Kesejahteraan Fatayat (YKF) didirikan oleh PW Fatayat DIY pada tahun 1992. Mendirikan YKF merupakan salah satu strategi PW Fatayat DIY ketika merasakan ada hambatan struktural dalam organisasi. Secara struktural PW Fatayat DIY di bawah PP Fatayat dalam semua kebijakan dan program. Sementara pengurus PW Fatayat DIY merasa telah memiliki wawasan dan pengalaman serta jaringan yang memungkinkan mereka menyusun kebijakan program tentang gender yang telah diusung oleh gerakan perempuan global sampai ke Indonesia, tak terkecuali ke DIY. Mendirikan YKF menjadi salah satu strategi yang digunakan ole PW Fatayat DIY karena dengan itu kebijakan program tentang gender dapat dan disusun dan dilaksanakan tanpa harus mempertanggungjawabkan kepada PP Fatayat. Terkait dengan hal ini, Marhamah menegaskan,

"ketika di sini tersumbat dalam pengertian struktural, YKF kan nonstruktural. Ketika ada program dan kegiatan-kegiatan yang harus tidak terlalu struktural maka YKF yang melaksanakan, sama dengan dulu PMII ketika PMII secata struktural ada hambatan kemudian ketua-ketua PMII mendirikan LKIS jadi begitu".

Pada awal berdirinya tahun 19921997, YKF menjadi bagian dari PW Fatayat DIY. YKF diprakarsai untuk lebih menguatkan peran Fatayat pada pemikiran dan gagasan dengan Fatayat memberikan contoh konkret kepada masyarakat tidak hanya melakukan dakwah bil lisan tetapi juga dakwah bil hal. YKF memulai kerja-kerja sosial untuk mendorong penguatan ekonomi bagi komunitas miskin di lingkungan NU. Daerah yang digarap saat itu adalah di pinggiran kali Code, Kulon Progo, dan Gunung Kidul. Program yang dilaksanakan oleh YKF tidak sebatas pada dataran wacana mengenai hak-hak perempuan akan tetapi melakukan tindakan langsung dengan praktik, seperti mendirikan rumah bersalin di Wonosari pada tahun 1993 yang dilengkapi dengan pusat konseling dan perpustakaan yang berkaitan kesehatan reproduksi. Hal ini sebagai bentuk dari praktik kepedulian Fatayat terhadap hak reproduksi perempuan. Runi menegaskan, "Inisiasi itu sudah kita bangun pada tahun 1992, tetapi seingat saya rumah bersalin itu sebagai cikal bakal adanya YKF itu tahun-tahun 1993 kita sudah rintis rumah bersalin, kita kerjasama dengan seorang bidan lalu dengan seorang dokter".

Program-program yang diakukan YKF secara struktural tidak berkaitan dengan kebijakan program PP Fatayat. Status otonom memberikan peluang kepada YKF untuk mengembangkan yayasan. Pengurus yayasan tidak lagi terbatas dari anggota Fatayat, akan tetapi berasal dari berbagai elemen masyarakat dan lebih bersifat multikultural. Runia menambahkan,

"Ya selain temen-temen perempuan yang dari Fatayat, juga temen-temen Anshor, kemudian temen-temen ikut PMII yang punya konsern sama untuk kerja dan cita-citanya dengan YKF saya ajak terlibat, selain juga ada temen-temen aktivis LSM yang kirakira punya visi sama dengan YKF gitu ya kami libatkan".

Pada tahun 1997 konferensi PW Fatayat DIY melakukan evaluasi terhadap eksistensi YKF dan memutuskan YKF 
sebagai lembaga otonom dari Fatayat DIY. YKF pada tahun 1997-2003 mandiri dari berbagai aspek. Isu yang diangkat cukup besar, melakukan seminar nasional, menulis dan menerbitkan buku, pelatihan dan workshop yang diselenggarakan mendatangkan banyak kiai dan nyai seluruh Jawa. Selain itu program-program juga berkaitan dengan Pimpinan Cabang Fatayat seperti untuk sosialisasi tentang gender. Isu program yang digarap oleh YKF sama dengan isu yang diangkat oleh PP Fatayat tetapi apa yang dilakukan oleh YKF tidak berkaitan dengan PP Fatayat.

YKF menginisiasi kebijakan dan program secara mandiri sehingga pada setiap pertemuan nasional Fatayat PW DIY menjadi semacam percontohan. DIY dipandang berbeda dengan wilayah lain. Oleh karena itu, PP Fatayat menyampaikan agar Fatayat wilayah dan daerah lain dapat mendirikan yayasan atau semacamnya sehingga mampu memberikan kontribusi terhadap organisasi baik di wilayah, cabang maupun anak cabang. YKF berkembang dan melintas wilayah DIY secara otonom. Sedangkan PW Fatayat tetap melaksanakan kebijakan yang menjadi program dari PP Fatayat. Sejak mendapatkan status otonom dari PW Fatayat hingga tahun 2002 YKF menyelenggarakan program yang berkaitan dengan Pengarusutamaan Gender dengan sasaran kalangan muda NU yang terakomodasi pada Badan Otonom NU dan Santri, serta pada pemimpinpeminpin pesantren melalui badal kiai dan badal nyai. Aktivitas yang dilakukan oleh YKF adalah dalam bentuk pelatihan, kajian rutin, dan advokasi kepada badal kiai dan badal nyai di wilayah DIY dan Jawa Tengah.

Konferensi PW Fatayat DIY tahun 2002 Fatayat memutuskan untuk menarik status otonom YKF kembali menjadi bagian dari PW Fatayat DIY. Konferensi
Fatayat DIY menyoal keberadaan YKF yang telah diberikan status otonom karena mempertimbangkan beberapa persoalan. Realitas YKF didirikan oleh PW Fatayat akan tetapi YKF sendiri tidak melihat YKF sebagai kepanjangtanganan Fatayat dalam upaya penyebarluasan isu-isu kesetaraan dan keadilan gender. Dalam perspektif YKF, PW Fatayat adalah pendiri yang diakui memiliki hubungan emosional tetapi bukan hubungan struktural yang dapat meminta pertanggungjawaban karena status otonom yang diberikan kepada YKF. Konflik antara PW Fatayat DIY dan YKF tidak menemukan titik temu. Hingga pada konferensi PW Fatayat DIY tahun 2002 diputuskan untuk menarik kembali YKF ke dalam struktur PW Fatayat DIY.

Mendirikan YKF merupakan ide kreatif dan inovatif yang dilakukan oleh Fatayat DIY untuk menghadapi kendala struktural organisasi yang mengharuskan kebijakan dan program turun dari pimpinan di tingkat atasnya. YKF yang berstatus otonom memungkinkan untuk bertindak secara proaktif terhadap gerakan-gerakan perempuan yang sedang semarak waktu awal digulirkan analisis gender sebagai pendekatan pembangunan. Adanya struktur organisasi Fatayat dari PP sampai ke pimpinan ranting tidak memungkinkan PW Fatayat DIY bertindak secara aktif menyusun kebijakan dan program yang belum diputuskan oleh pimpinan pusat.

Kebijakan keluar dari struktur organisasi dengan status otonom memberikan banyak peluang pada YKF untuk menyusun kebijakan dan programprogram aktual keperempuanan yang sedang gencar ditawarkan oleh fundingfunding dari luar negeri seperti Ford Foundation. Juga dalam melaksanakan program, YKF tidak perlu berkoordinasi 
secara langsung dengan Fatayat. Kemampuan Individu-individu pimpinan PW DIY menangkap peluang dan tanggap terhadap persoalan yang sedang bergulir secara global menjadi salah satu faktor menentukan bagi pentingnya YKF bergerak secara otonom.

Dari sisi struktur, status otonom YKF menjadi sebuah penyimpangan akan tetapi dari sisi kepentingan dan kebutuhan saat itu menjadi sebuah keharusan. Deviasi srtuktural masih dapat diterima Fatayat dengan diakuinya YKF dalam berbagi forum nasional dan bahkan menjadi percontohan bagi wilayah-wilayah lain di Indonesia. Namun, persoalan kultural menjadi hal yang lebih penting dari struktural. Menyimpang secara struktural dapat diterima, akan tetapi ketika secara kultural berbeda visi, misi, nilai, dan norma hal ini menjadi persoalan yang dinilai lebih serius oleh Fatayat. Ketika YKF melibatkan berbagai elemen lembaga swadaya masyarakat yang berbeda visi dan misi dengan Fatayat apalagi dengan nilai dan norma yang dinilai tidak sejalan dengan Fatayat, maka ini menjadi persoalan. Hal ini yang mendorong Fatayat DIY mencabut status otonom YKF dan menempatkan kembali YKF dalam struktural organisasi.

YKF lahir dari Fatayat yang memiliki nilai dan norma Islam yang bersumber kepada Alquran dan Sunnah. Di satu sisi YKF sebagai yayasan merasa telah diberi hak otonomi seluas-luasnya untuk mengembangkan diri termasuk mengembangkan visi, misi maupun nilainilai dan norma. Sesungguhnya YKF dalam hal ini tidak dapat lepas dari Fatayat dilihat dari berbagai aspek: (1) Dilahirkan oleh Fatayat DIY; (2) Menggunakan nama Fatayat (Yayasan Kesejahteraan Fatayat); (3) Orang mengenal YKF sebagai Fatayat, dengan kata lain YKF identik dengan Fatayat. Ketiga hal tersebut tidak dapat dinafikan keberadaannya. Menjaga nilai-nilai dan norma agama dipandang jauh lebih penting oleh Fatayat daripada mengikuti gerakan kesetaraan dan keadilan yang menempatkan hak-hak perempuan pada kebebasan yang tidak dibingkai oleh nilai-nilai dan norma agama yang telah dipahami dan diikuti.

\section{SIMPULAN}

Adopsi kebijakan PUG di organisasi Fatayat DIY menunjukkan adanya faktor penentu internal dan eksternal. Faktor internal meliputi: (a) kebutuhan individu pada konsep kesetaraan dan keadilan; (b) relevan dengan nilai-nilai dan norma agama; (c) karakteristik terbuka pada pemimpin opini dalam organisasi; dan (d) struktur organisasi. Faktor eksternal meliputi: (a) sikap NU sebagai organisasi induk dengan memberikan restu menjadi penentu utama dalam proses ini; (b) gencarnya gerakan perempuan di luar Fatayat; dan (c) dukungan dana dari luar negeri.

Proses inovasi kebijakan PUG dalam organisasi meliputi tahap setting agenda, penyesuaian, mendefinisikan kembali, mengklarifikasi, dan rutinisasi. Rutinisasi yang dilakukan pada tahun 2000-2010 menjadikan PUG sebagai bagian dari aktivitas organisasi.

Partisipasi di bidang politik merupakan dampak langsung dari adopsi pengarusutamaan gender dalam organissi Fatayat. Yayasan Kesejahteraan Fatayat (YKF) memiliki peran yang strategis pada awal difusi Kebijakan PUG hingga ditariknya kembali YKF ke dalam struktur organisasi Fatayat. Dengan terjadinya adopsi terhadap kebijakan PUG menjadikan identitas Fatayat sebagai organisasi perempuan tradisional dengan aktivitas dari "ngaji ke ngaji” mulai hilang. 
Fatayat bukan lagi sekelompok perempuan muda pedesaan yang termarginalkan dalam informasi tetapi telah berubah menjadi kelompok perempuan muda yang progresif dan inovatif serta mampu menjadi penggerak bagi perempuan lain di sekitarnya.

\section{DAFTAR PUSTAKA}

Daft, R. L. 1978. "A Dual-Core Model of Organizational Innovation". Academy of Management Journal, 21(2), 193210.

Damanpour, F. 1996. "Organizational and Innovation: Developing and Testing Multiple Contingensi Models". Journal Management Science, 42(5), 694-716.

Damanpour, F., \& Evan, W. M. 1984. "Organizational Innovation and Performance: The Problem of "Organizational Lag"'. Administrative Science Quarterly, 29, 392-409.

Greenhalgh, T., Robert, G. Macfarlane, F., Bate, P., \& Kyrjakidou, O. 2004. "Diffussion of Innovation in Service Organizations: Systematic Review and Recommendation". Journal The Milbank Quarterly, 4, 581-629.

Hajaroh, M. 2012. "Difusi Kebijakan Pengarusutamaan Gender di Fatayat
Nahdlatul Ulama Daerah Istimewa Yogyakarta". Disertasi. Program Pascasarjana Universitas Negeri Yogyakarta.

Havelock, R. G. (tth). Planning for Innovation: Through Dissemination and Utilization of Knowledge. Michigan: Center for Research on Utilization of Scientific Knowledge.

Instruksi Presiden Republik Indonesia (INPRES) Nomor 9 Tahun 2000 $(9 / 2000)$ tentang Pengarusutamaan Gender dalam Pembangunan Nasional.

PP Fatayat. 2000. Keputusan Konggres XII Fatayat. Jakarta: PP Fatayat.

Rogers, E. M. 2003. Diffusion of Innovations. New York: The Free Press.

True, J. , \& Mintrom, M. 2001. "Transnational Network and Policy Diffusion: The Case of Gender Mainstreaming". Journal International Studies Quarterly, 45(1), 27-57.

Undang-Undang Nomor 10 Tahun 2008 tentang Pemilu Legislatif.

Yalcinkaya, G. 2007. "Understanding the Emergence of Aggregate Level Innovation Diffusion through Individual Level". Dissertation. USA: Michigan State University. 